Justyna MOLENDA, Adam CHARCHALIS

Gdynia Maritime University (Uniwersytet Morski w Gdyni)

\title{
PRELIMINARY RESEARCH OF POSSIBILITY OF USING THERMOVISION FOR DIAGNOSIS AND PREDICTIVE MAINTENANCE OF MARINE ENGINES
}

\author{
Badania wstępne zastosowania metod termowizyjnych \\ do diagnostyki i predykcyjnego utrzymania \\ ruchu silnika okrętowego
}

\begin{abstract}
Infrared thermography has evolved as an effective condition monitoring tool for real-time temperature monitoring of objects or processes in a noncontact way. This paper presents the results of research conducted with use of infrared camera for monitoring 3AL25/30 engine, especially turbocharger, placed in Marine Engineering Faculty of Gdynia Maritime University. Research was carried out using a thermal camera NEC Thermo Gear G100 with appropriate software. Test results improved that infrared thermography is useful also for monitoring the condition of ship engine equipment, and enable anticipating failures during engine work.

Keywords: infrared thermography, technical diagnostics, monitoring, predictive maintenance, internal combustion engines

Streszczenie: Termografia $w$ podczerwieni rozwinęła się jako skuteczne narzędzie bezkontaktowego monitorowania stanu obiektów lub procesów w czasie rzeczywistym, poprzez badanie temperatury i jej rozkładu na powierzchni monitorowanych maszyn i urzadzeń. W artykule przedstawiono wyniki badań, w których wykorzystano kamerę termograficzna do monitorowania stanu technicznego (cieplnego) silnika okrętowego, w szczególności turbosprężarki, na przykładzie silnika laboratoryjnego 3AL25/30. Badania zrealizowano za pomoca kamery firmy NEC, Thermo Gear G100. Wyniki badań dowiodty, że termografia $w$ podczerwieni jest przydatna $w$ monitorowaniu stanu silnika okrętowego i umożliwia wykrycie nieprawidłowości w czasie pracy silnika.
\end{abstract}

Słowa kluczowe: termografia w podczerwieni, diagnostyka techniczna, monitoring, predykcyjne utrzymanie ruchu, silniki spalinowe 


\section{Introduction}

Temperature is one of the major diagnostic parameters. It can be a valuable source of diagnostic information about technical condition of elements, whole machines and devices and course of processes and phenomena. Checking temperatures of engine room components is also everyday duty of each watch keeping engineer. There are several methods for temperature measuring, among them infrared (IR) thermography. IR thermography allows to see what human eyes cannot. Each body with a temperature above absolute zero emits heat, portion of the electromagnetic energy. Infrared cameras produce images of invisible infrared or "heat" radiation and provide precise non-contact temperature measurement capabilities. An image produced by an infrared camera is called a thermogram (fig. 1).
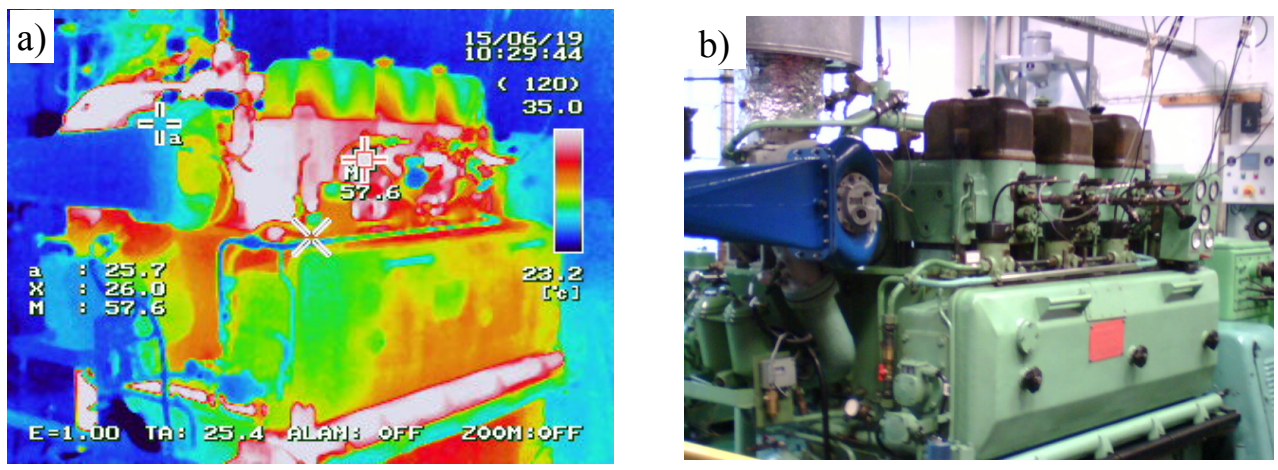

Fig. 1. The exemplary thermogram of $3 A L 25 / 30$ engine: a) IR view, b) visible picture

Thermography is not a new phenomenon - it has been utilized successfully in industrial and research settings for decades. Originally developed for military use during the Korean War, IR thermography cameras has become a powerful tool for basic and applied scientific research and for the application in various fields such as industry, environment, military and maritime affairs, etc. A recent advance in IR sensor production and a reduction in prices have helped the infrared viewing technology to be adopted as a cost-effective, non-invasive measuring method. Advanced optics and sophisticated software interfaces continue to add to the variety of thermal IR cameras. Today, the IR thermography is applied in numerous human activities, such as: astronomy (telescope), fire fighting operations, military and police surveillance, target detection and acquisition, law enforcement and antiterrorism, predictive engineering maintenance of mechanical and electrical equipment, process monitoring, condition monitoring and surveillance, energy 
auditing of insulation, roof inspection, masonry wall structural analysis, moisture detection in walls and roofs, medical testing for diagnosis, non-destructive testing, quality control in production environments, research and development of new products, effluent pollution detection, locating of unmarked graves, aerial archaeology, search and rescue operations, etc. $[1,3,4,5,6]$.

Main advantages of IR thermography are:

- allowing taking corrective actions before electrical, mechanical, or process equipment fails (prevention). Most failures in equipment are signalled by a significant rise in operating temperature long before failure occurs;

- getting a visual picture for an analysis and comparison of temperatures over a large area;

- catching moving targets in real time (video rate);

- enabling measurement in inaccessible areas or areas hazardous for other test methods [6].

- Some limitations and disadvantages of IR thermography are:

- thermal images need experience and special tools to be interpreted correctly,

- very accurate temperature measurements are hard to make because of changes in materials emissivity,

- training for and developing proficiency in the IR scanning is time consuming [6].

In the marine industry, thermal imaging can be used to detect delamination in hulls, bad core material under layers of fiberglass, leaking tanks, overheating wiring, water not flowing properly through heat exchangers or engine blocks, faulty pumps, etc. These anomalies that are typically easily found with the thermal imaging camera can save thousands of dollars.

\section{Predictive Maintenance of ship engine}

Maritime industry, today, focuses largely on having minimal shipboard failures, defects or breakdowns. Unplanned accidents are unavoidable but the least can be done is to prevent them from happening by way of predicting and analysing a future trend of the machine. This is enabled by more than 60 years' development of the inspection and maintenance technologies. To detect the problem and avoid the failure very important and essential is to develop the Non Destructive Testing (NDT) and Condition Monitoring including vibration analysis, oil analysis, ultrasonic analysis and thermal analysis. The analysis of current or actual condition of equipment can be taken when it is 'in-service'. On ships that employ a limited crew, time management, utilizing available resources and prioritising important tasks is imperative to the proper 
functioning of the vessel. Condition Based Monitoring makes the job even simpler since the task is carried out with minimal intervention while the machinery is in its normal operating mode. If worked upon, a well engineered condition based maintenance program will prove successful to optimally manage a time bound work culture on board ships. According to Emerson Process Management materials [2] Belgian Navy saves 1.5 million Eurodollars per year by applying predictive maintenance in seven minehunters. Additionally the mean time between maintenance (MTBM) for gas turbines is extended from 2500 to 4000 hours.

As a 'predictive' maintenance tool for ships power plants, IR thermography has the ability to identify problems before they occur. It is especially helpful for trouble shooting potential electrical overloads, worn or bad circuit breakers and buses. IR thermography can also be used to detect bad bearings, shafts, worn pulleys or any application where heat detection would be beneficial $[2,6,7]$.

\section{Experimental setup}

The research was carried out on 3AL25/30 laboratory engine, placed in Marine Engineering Faculty of Gdynia Maritime University. This is 3-cylinder, medium speed, self-ignition engine which drives electro-generator. It is equipped with top class operating station enabling monitoring and recording of working parameters. The operating station EMOS is dedicated to current control, visualization and archive of the working parameters of the engine and also enables remote control of the engine and auxiliaries. General view of both laboratory engine and operating station are shown in fig. 2.
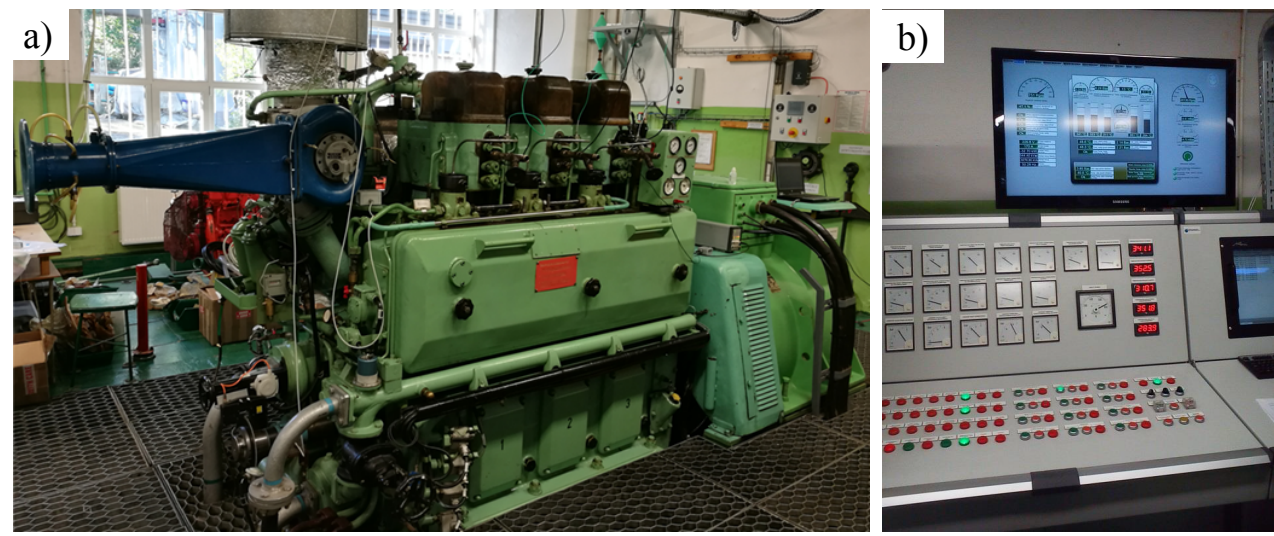

Fig. 2. Experimental setup: a) 3AL25/30 engine, b) EMOS station general view 
Temperature was measured by infrared camera Thermo Gear G100 produced by NEC Avio Infrared Technologies CO., Ltd (fig. 3). The camera serves for contact-less, remote temperature measurement and visualization of its distribution. As a result of a measurement it is obtained a data set that is presented in a form of a colour map: a thermogram. The thermogram consists of 76800 measuring points (320 points in 240 lines). Two measuring ranges are defined: $-40-120$ and $0-$ $500^{\circ} \mathrm{C}$. The measurement accuracy is $\pm 2^{\circ} \mathrm{C}$ or $2 \%$ of reading, whichever is greater. The camera employs a gun grip design with a rotatable monitor similar to that of a video cameras, which enables one-hand operation. The image capture support functions of a 2-megapixel visible camera.

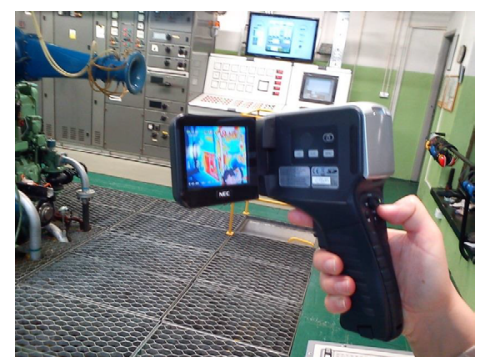

Fig. 3. Thermo Gear G100 camera

Thermograms were obtained during normal engine work with three different load: $64 \mathrm{~kW}, 126 \mathrm{~kW}, 279 \mathrm{~kW}$. Temperature distribution on chosen elements: turbocharger and one cylinder head was recorded.

\section{The research results}

The thermograms showing temperature distribution on surface of turbocharger obtained for different loads are shown in figs. 4-6. The figures consist also pictures made by means of visibile camera built-in Thermo Gear G100.

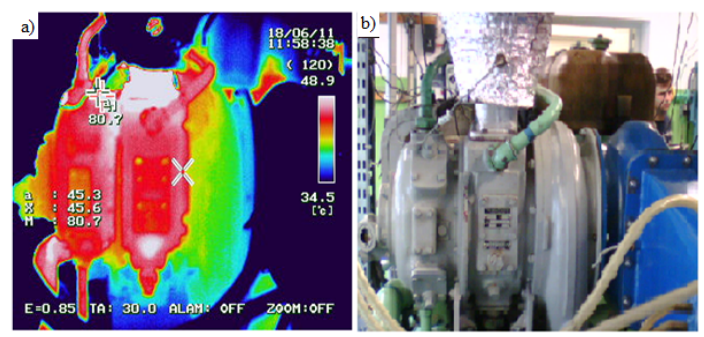

Fig. 4. Results for engine work with load $64 \mathrm{~kW}$; turbocharger: a) thermogram, b) visible picture 

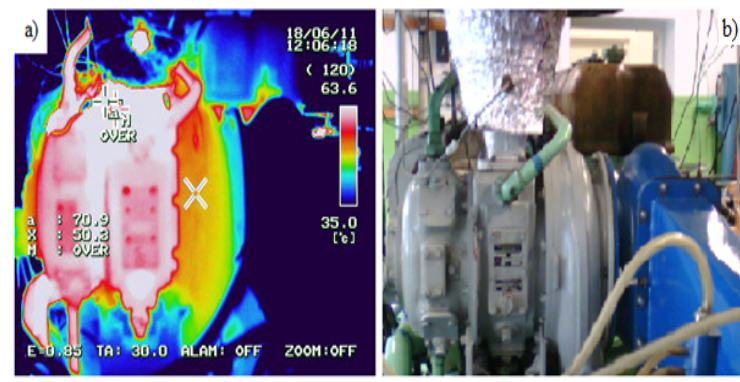

Fig. 5. Results for engine work with load $126 \mathrm{~kW}$; turbocharger: a) thermogram, b) visible picture

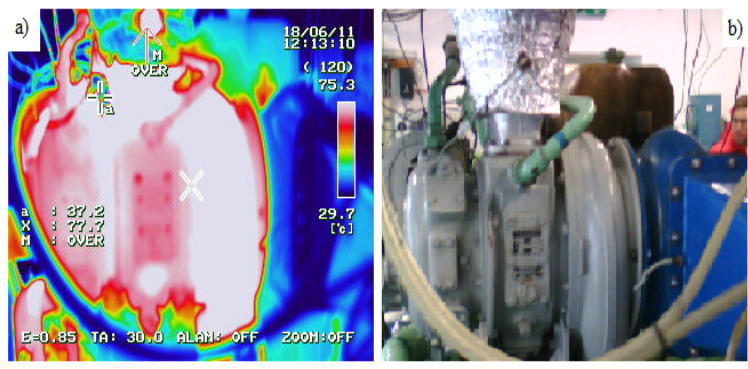

Fig. 6. Results for engine work with load $279 \mathrm{~kW}$; turbocharger: a) thermogram, b) visible picture

Further results presented in figs. 7-9 show temperature distribution on cylinder head and cylinder liner for different engine loads. Figure 10 presents additional thermogram made after opening the indicator cock. It was made during engine operating with load $54 \mathrm{~kW}$.
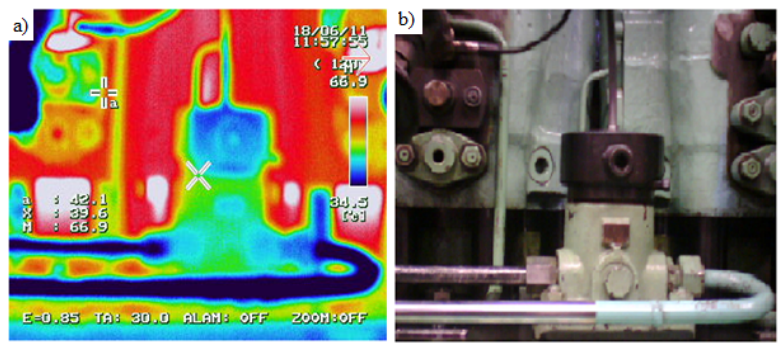

Fig. 7. Results for engine work with load $64 \mathrm{~kW}$; cylinder liner and head: a) thermogram, b) visible picture 

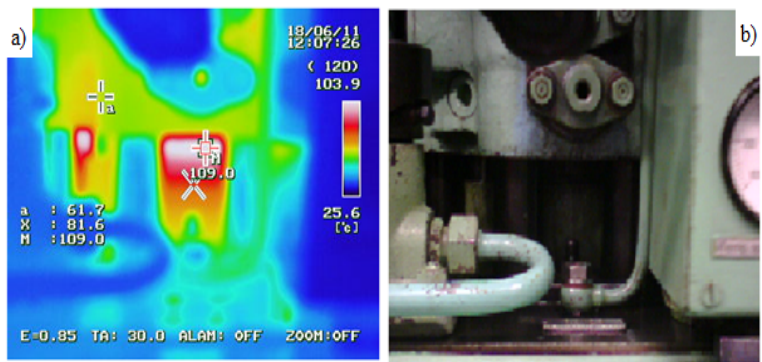

Fig. 8. Results for engine work with load $126 \mathrm{~kW}$; cylinder liner and head: a) thermogram, b) visible picture
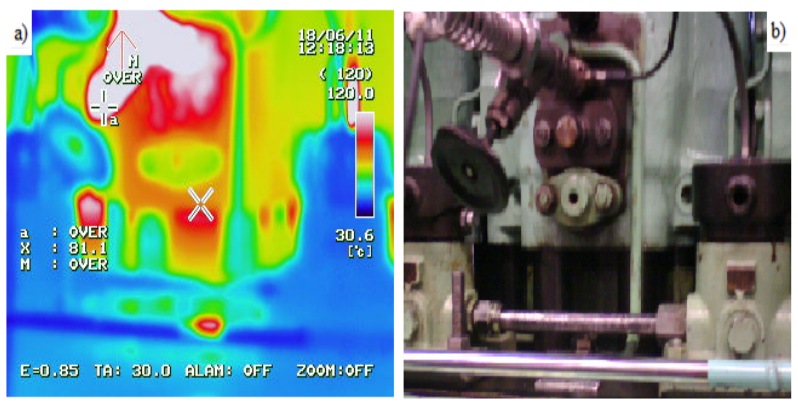

Fig. 9. Results for engine work with load $279 \mathrm{~kW}$; cylinder liner and head: a) thermogram, b) visible picture
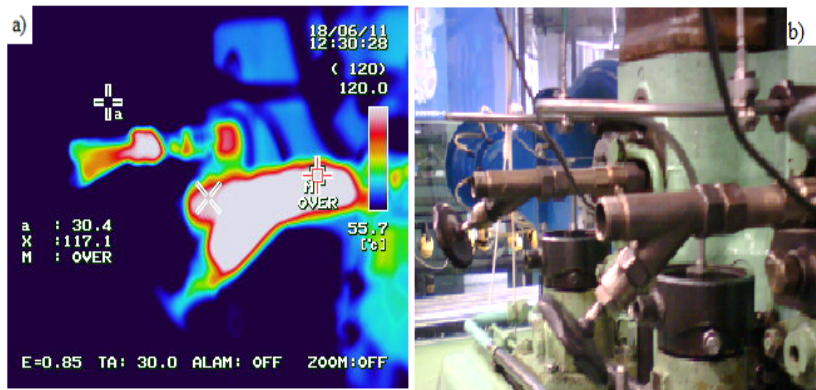

Fig. 10. Results for engine work with load $54 \mathrm{~kW}$ after indicator cock opening: a) thermogram, b) visible picture 


\section{Conclusions}

The numerous advantages offered by noncontact temperature measurement have led this technology to become an area of interest for new kinds of applications and users. There are lots of things an infrared thermography can be used for in engine room. In 2004, Loyd's Register, the world's most important ship classification and certification body, made the following prediction: 'In the near future, mechanical machinery on board vessels will also benefit from thermal imaging, especially as a pre-docking strategy to identify and target equipment and systems which need attention as well as to eliminate unnecessary work'. Now IR thermography can do much more. There are numerous components that require temperature monitoring, either by touch, temperature gauges, pyrometers or pocket thermometers. A handheld infrared camera would complement these methods through confirming temperatures and showing it's distribution not only the value in one point.

\section{References}

1. Dudzik K., Charchalis A.: Wykorzystanie emisji akustycznej do diagnozowania wtryskiwacza silnika 3AL25/30 [The use of acoustic emission for the diagnosis of 3AL25/30 engine fuel injector]. Logistyka, No. 3, 2015.

2. https:/www.emerson.com/documents/automation/case-study-belgian-navy-savesbig-money-predictive-maintenance-based-on-vibration-monitoring-oil-analysis-amsen-38550.pdf

3. Minkina W.: Pomiary termowizyjne - przyrządy i metody [Infrared thermography measurements - instruments and methods]. Wydawnictwo Politechniki Częstochowskiej, 2004.

4. Molenda J., Charchalis A.: The influence of the temperature of the elements of the lapping machine executory system on the results of the lapping process. Solid State Phenomena. 2015, Vols. 220-221.

5. Molenda J., Charchalis A.: Using thermovision for temperature measurements during turning process. Journal of Kones, Vol. 25, No. 4, 2018.

6. Pasagic V., Muzevic M., Kelenc D.: Infrared Thermography in Marine Applications. Brodogradnja, 2 (59), 2008.

7. Singh B.: Can effective predictive maintenance be more beneficial on board ships? Marine Insight (https://www.marineinsight.com/tech/predictive-maintenance-onboard-ships/). Updated April 2019. 


\section{BADANIA WSTĘPNE ZASTOSOWANIA METOD TERMOWIZYJNYCH DO DIAGNOSTYKI I PREDYKCYJNEGO UTRZYMANIA RUCHU SILNIKA OKRETOWEGO}

\section{Wprowadzenie}

Temperatura jest jednym $\mathrm{z}$ podstawowych parametrów diagnostycznych. Może być cennym źródłem informacji o stanie technicznym części, całych maszyn i urządzeń oraz przebiegu różnych procesów i zjawisk. Pomiar i kontrola temperatury elementów siłowni okrętowej jest codziennym obowiązkiem oficera wachtowego. Zastosowanie znajdują liczne metody pomiaru temperatury, wśród nich metody termowizyjne. Termografia w podczerwieni obrazuje to, co jest niewidoczne dla ludzkiego oka. Każde ciało o temperaturze wyższej od temperatury zera bezwzględnego emituje promieniowanie elektromagnetyczne. Kamery termowizyjne odbierają to promieniowanie, tworzą jego obraz i umożliwiają zdalny pomiar temperatury na powierzchni badanego obiektu. Obraz generowany przez kamerę nazywa się termogramem (rys. 1).
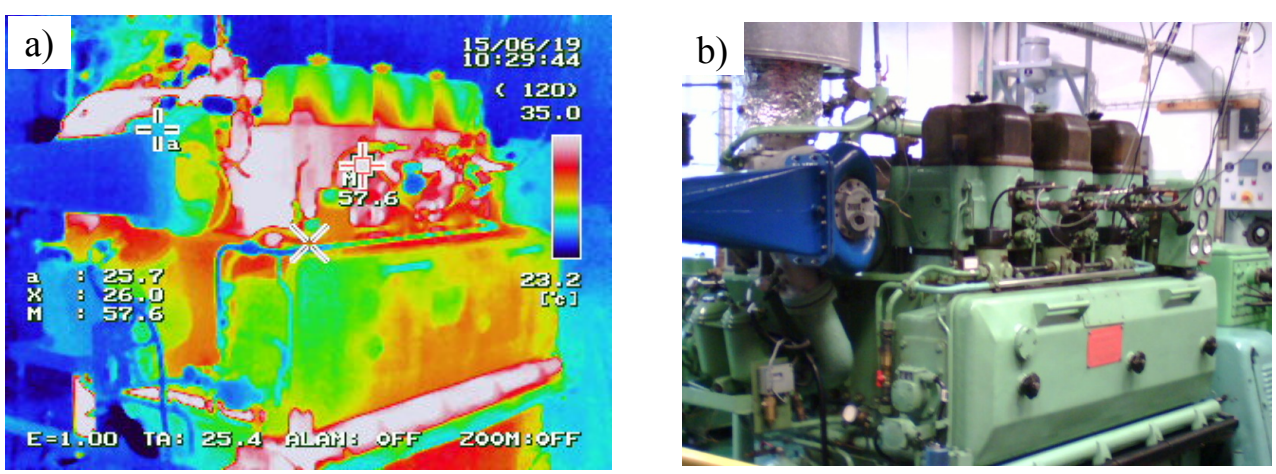

Rys. 1. Obraz silnika laboratoryjnego 3AL25/30: a) w podczerwieni, b) widzialny

Termografia jest efektywnie wykorzystywana w przemyśle i badaniach naukowych od dziesięcioleci. Początkowo stosowane i rozwijane przez przemysł 
zbrojeniowy kamery termowizyjne $\mathrm{z}$ czasem stały się potężnym narzędziem w badaniach podstawowych i stosowanych oraz w innych obszarach, jak przemysł, środowisko, wojskowych, morskich i wielu innych. Gwałtowny postęp w produkcji detektorów podczerwieni oraz spadek ich cen sprawiły, że termowizja stała się niskokosztową, nieinwazyjną metodą pomiaru temperatury. Zaawansowana optyka i rozbudowane oprogramowanie dodatkowo poszerzają zastosowania kamer termowizyjnych. Obecnie, termografia $\mathrm{w}$ podczerwieni znajduje zastosowanie w niemal każdym obszarze aktywności człowieka: astronomii, ochronie przeciwpożarowej, służbie wojskowej i policyjnej, poszukiwaniu i lokalizacji obiektów, działaniach antyterrorystycznych, predykcyjnym utrzymaniu ruchu maszyn i urządzeń mechanicznych i elektrycznych, monitorowaniu przebiegu procesów, kontroli i nadzorze stanu obiektów, audycie energetycznym izolacji, kontroli dachu, analizie strukturalnej ścian murowanych, wykrywania wilgoci w ścianach i dachach, diagnostyce w badaniach medycznych, badaniach nieniszczących, kontroli jakości w środowiskach produkcyjnych, badaniach i rozwoju nowych produktów, wykrywaniu zanieczyszczeń ścieków, lokalizowaniu nieoznaczonych grobów, archeologii lotniczej, operacjach poszukiwawczych i ratowniczych $i$ in. $[1,3,4,5,6]$.

Termografia w podczerwieni ma wiele zalet, w tym:

- pozwala podjąć działania korygujące (zapobiegawcze) przed wystąpieniem awarii elektrycznego i mechanicznego zaplecza realizowanych procesów. Większość awarii jest sygnalizowana na długo przed wystąpieniem znacznego wzrostu temperatury;

- w wyniku pomiaru otrzymuje się obraz, który umożliwia analizę i porównanie temperatury na większym obszarze;

- pozwala badać obiekty ruchome w czasie rzeczywistym (szybkość filmu);

- umożliwia pomiar w miejscach niedostępnych lub niebezpiecznych dla innych metod pomiarowych [6].

- Istnieją również pewne ograniczenia i wady tej metody, w tym:

- prawidłowa interpretacja termogramów wymaga doświadczenia i specjalnych narzędzi,

- ze względu na zmiany emisyjności materiałów, trudno wyznaczyć bardzo dokładną wartość temperatury,

- osiągnięcie biegłości w wykonywaniu pomiarów temperatury z zastosowaniem urządzeń termowizyjnych jest czasochłonne [6].

W przemyśle morskim termografia znajduje zastosowanie w detekcji rozwarstwień kadłuba, błędów materiału rdzenia pod warstwami włókna szklanego, przecieków w zbiornikach, przegrzanych przewodów elektrycznych, nieprawidłowego przepływu czynników w wymiennikach ciepła lub w bloku silnika, awarii 
pomp i in. Zastosowanie kamer termograficznych do wykrywania tego rodzaju anomalii pozwala zaoszczędzić tysiące dolarów.

\section{Predykcyjne utrzymanie ruchu silnika okrętowego}

Przemysł okrętowy skupia się dzisiaj głównie na zminimalizowaniu występowania usterek, awarii i uszkodzeń. Nieplanowane awarie są nie do uniknięcia, jednak można próbować im zapobiegać poprzez przewidywanie i analizę przyszłego użytkowania maszyn. Jest to możliwe dzięki ponad 60letniemu rozwojowi metod inspekcji i utrzymania ruchu. Wykrywanie problemów zanim spowodują awarię, umożliwił rozwój nowych metod badań nieniszczących (NDT) i monitorowania stanu, w tym badań wibracji, próbek oleju, ultradźwiękowych i temperaturowych. Badania stanu technicznego wyposażenia z wykorzystaniem tych metod można prowadzić w trakcie normalnej pracy urządzeń. Dla prawidłowego funkcjonowania statku, gdy ograniczona jest liczba załogi, szczególne znaczenie mają zarządzanie czasem, optymalne wykorzystanie zasobów i ustalanie ważności zadań. W tym przypadku monitorowanie stanu technicznego maszyn i urządzeń usprawnia pracę, ponieważ czynności obsługowe można zaplanować i wykonać tak, by nie zakłócać ich normalnej eksploatacji. Jeżeli zostanie opracowany dobrze przemyślany, oparty na stanie technicznym, plan obsługi, jego wdrożenie przyniesie wymierne korzyści nie tylko związane $\mathrm{z}$ właściwym zarządzaniem czasem, ale również finansowe. Zgodnie z danymi podanymi przez firmę Emerson Process Management [2] belgijska marynarka wojenna, dzięki wdrożeniu predykcyjnego utrzymania ruchu na siedmiu niszczycielach, oszczędza ok. 1,5 miliona eurodolarów rocznie. Korzyści finansowe wynikają m.in. z wydłużenia średniego czasu między remontami (MTBM) dla turbin gazowych z 2500 do 4000 godzin.

Jako narzędzie predykcyjnego utrzymania ruchu, termografia w podczerwieni umożliwia wykrycie problemów, zanim faktycznie wystąpią. Szczególnie nadaje się do wykrywania przegrzania przewodów elektrycznych, zużycia i nieprawidłowego działania włączników, łożysk, wałów, zużytych kół pasowych i wszelkich innych problemów, które poprzedza i którym towarzyszy zmiana temperatury $[7,2,5]$. 


\section{Stanowisko badawcze}

Badania przeprowadzono na silniku laboratoryjnym 3AL25/30 stanowiącym wyposażenie Wydziału Mechanicznego Uniwersytetu Morskiego w Gdyni. Jest to 3-cylindrowy silnik średnioobrotowy z zapłonem samoczynnym, napędzający prądnicę. Silnik wyposażony jest w komputerowy układ pomiarowy typu EMOS. System jest dedykowany do bieżącej kontroli, wizualizacji i archiwizowania parametrów pracy silnika. Dodatkowo umożliwia zdalne sterowanie silnikiem i urządzeniami pomocniczymi. Na rys. 2 przedstawiono silnik i panel operatora.
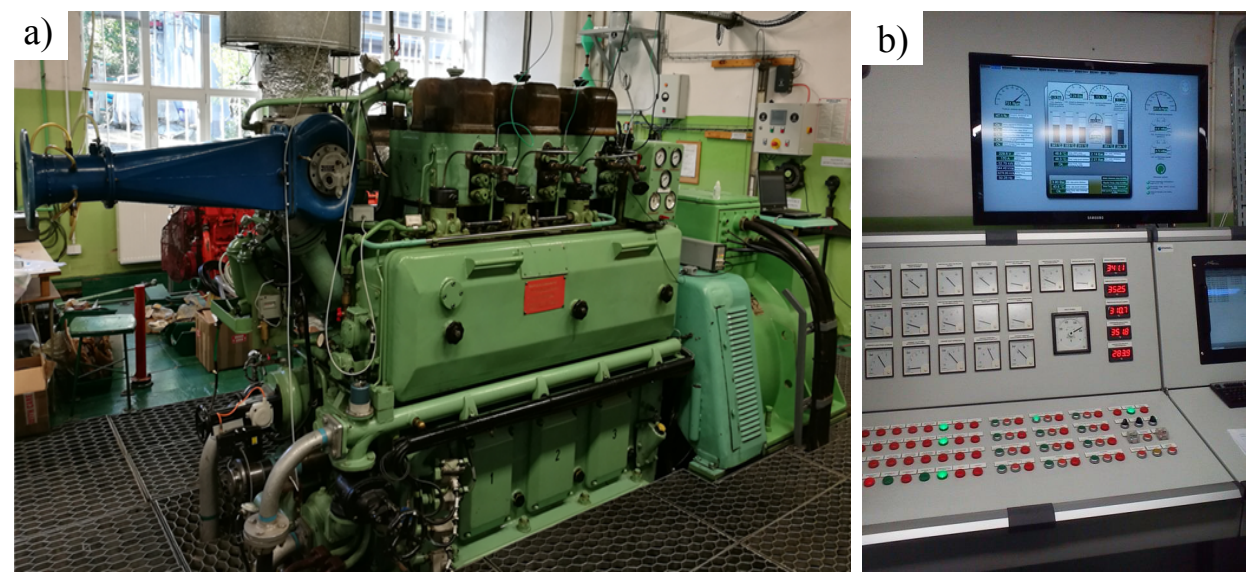

Rys. 2. Stanowisko badawcze: a) silnik 3 AL25/30, b) stanowisko kontrolne

Pomiary temperatury wykonywano kamerą termowizyjną Thermo Gear G100 firmy NEC Avio Infrared Technologies CO., Ltd (rys. 3). Kamera umożliwia zdalny, bezkontaktowy pomiar temperatury na powierzchni badanego elementu oraz zobrazowanie jej rozkładu. W rezultacie przeprowadzonego pomiaru uzyskuje się zestaw danych w postaci kolorowej mapy - termogramu. Termogram zawiera dane z 76800 punktów pomiarowych (320 punktów w 240 liniach). Możliwy jest pomiar $w$ dwóch zdefiniowanych zakresach temperatur: $-40 \div 120$ i $0 \div 500^{\circ} \mathrm{C}$. Dokładność pomiaru wynosi $\pm 2{ }^{\circ} \mathrm{C}$ lub $2 \%$ odczytu. Jej niewielka masa (ok. $800 \mathrm{~g}$ z baterią), anatomiczny kształt pistoletu oraz obrotowy 3,5" ekran LCD ułatwiają obsługę jedną ręką. Kamera wyposażona jest również w aparat widzialny o rozdzielczości 2 mln pikseli, dzięki czemu poza rejestracją obrazu termicznego, możliwa jest rejestracja obrazu widzialnego. 


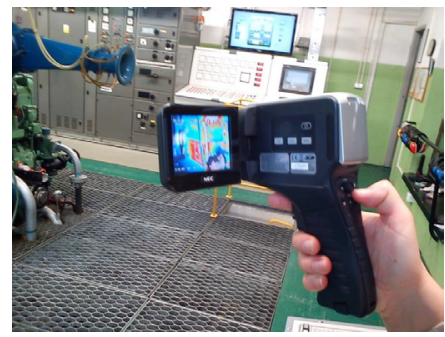

Rys. 3. Kamera termowizyjna Thermo Gear G100

Termogramy uzyskano $\mathrm{w}$ trakcie normalnej pracy silnika $\mathrm{z}$ trzema różnymi obciążeniami: $64 \mathrm{~kW}, 126 \mathrm{~kW}, 279 \mathrm{~kW}$. Rejestrowano rozkład temperatury na powierzchni wybranych elementów: turbosprężarki, głowicy i tulei cylindrowej.

\section{Wyniki badań}

Termogramy przedstawiające rozkład temperatury na powierzchni turbosprężarki uzyskane dla różnych obciążeń silnika przedstawiono na rys. 4-6. Rysunki poza termogramami, zawierają również obraz widzialny badanego obszaru, wykonany wbudowanym w kamerę aparatem optycznym.

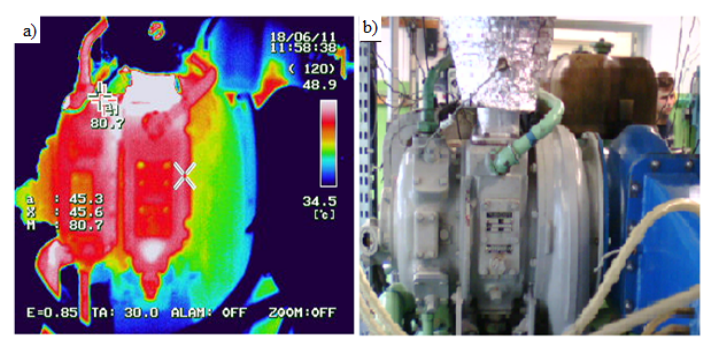

Rys. 4. Wyniki dla obciążenia $64 \mathrm{~kW}$; turbosprężarka: a) termogram, b) obraz widzialny
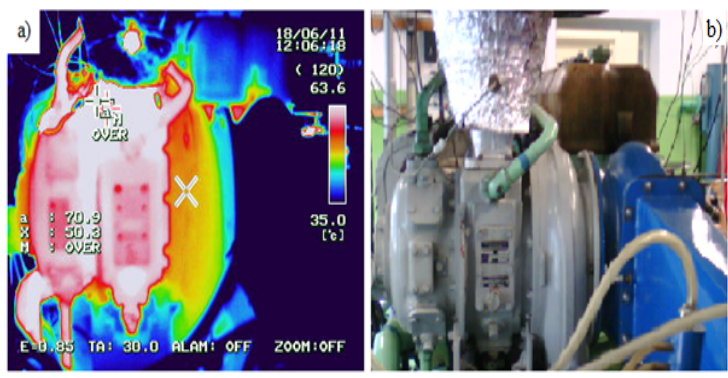

Rys. 5. Wyniki dla obciążenia $126 \mathrm{~kW}$; turbosprężarka: a) termogram, b) obraz widzialny 


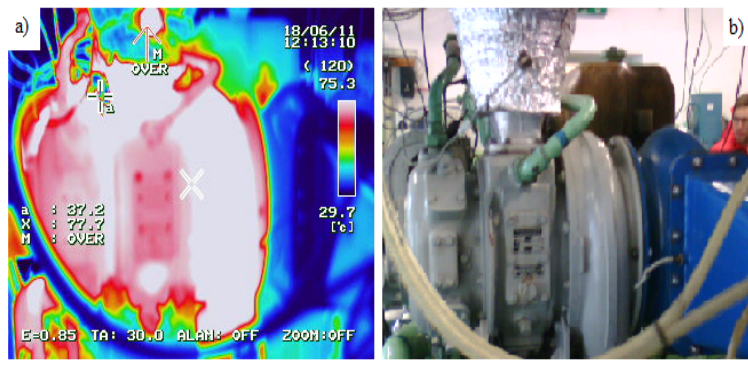

Rys. 6. Wyniki dla obciążenia $279 \mathrm{~kW}$; turbosprężarka: a) termogram, b) obraz widzialny

Dalsze wyniki, zaprezentowane na rys. 7-9, przedstawiają rozkład temperatury na powierzchni głowicy cylindrowej i tulei cylindrowej, dla różnych obciążeń silnika. Na rys. 10 dodatkowo przedstawiono termogram wykonany przy otwartym kurku indykatorowym i obciążeniu $54 \mathrm{~kW}$.
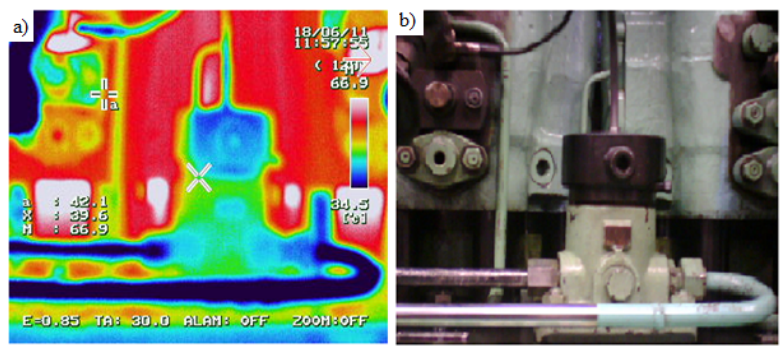

Rys. 7. Wyniki dla obciążenia $64 \mathrm{~kW}$; tuleja cylindrowa i głowica: a) termogram, b) obraz widzialny
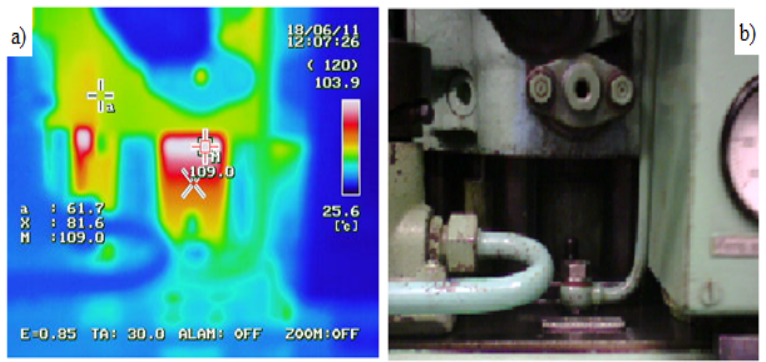

Rys. 8. Wyniki dla obciążenia $126 \mathrm{~kW}$; tuleja cylindrowa i głowica: a) termogram, b) obraz widzialny 

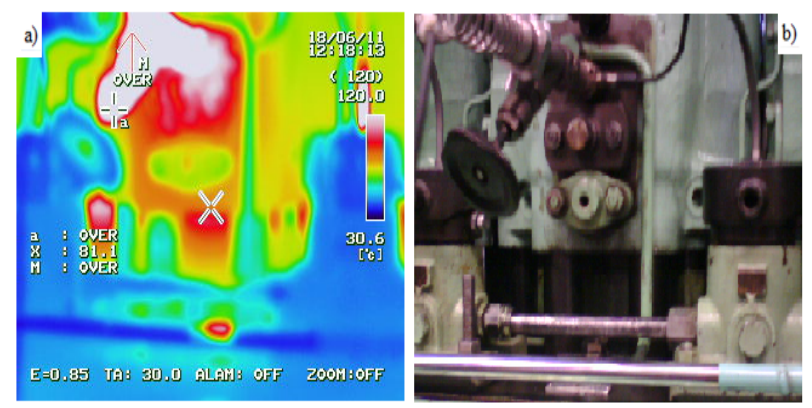

Rys. 9. Wyniki dla obciążenia $279 \mathrm{~kW}$; tuleja cylindrowa i głowica: a) termogram, b) obraz widzialny
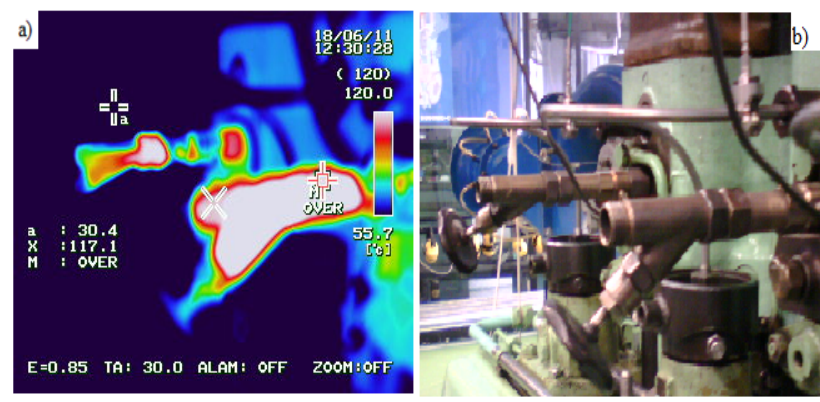

Rys. 10. Wyniki dla obciążenia $54 \mathrm{~kW}$ przy otwartym kurku indykatorowym:

a) termogram, b) obraz widzialny

\section{Wnioski}

Liczne zalety zdalnego pomiaru temperatury spowodowały, że ta technika stale zyskuje nowych użytkowników i nowe zastosowania. Istnieje wiele możliwości zastosowania metod termowizyjnych w siłowni okrętowej. W 2004 Loyd's Register, jedno z najważniejszych towarzystw klasyfikacyjnych i certyfikujących na świecie, zapowiedziało: „w najbliższej przyszłości urządzenia mechaniczne na statkach również będą korzystać z obrazowania termicznego, zwłaszcza w czasie normalnej eksploatacji, w celu zidentyfikowania urządzeń i systemów, które wymagają przeprowadzenia czynności obsługowych oraz w celu wyeliminowania niepotrzebnego nakładu pracy”. Obecnie termografia w podczerwieni znaczy dużo więcej. Istnieje wiele urządzeń, które wymagają monitorowania temperatury. W warunkach siłowni wykorzystuje się do tego dotyku, czujników temperatury, pirometrów lub kieszonkowych termometrów. Poręczna, niewielka kamera 
termograficzna byłaby dobrym uzupełnieniem tego zestawu i mogłaby służyć do potwierdzania odczytanych wartości temperatury oraz przedstawiania rozkładu temperatury na większym obszarze, nie tylko w punkcie.

W układzie sprzężonego powietrza pomiary AE przeprowadzone po naprawie nieszczelnego zaworu wykazały dobrą kondycję zbiornika i pozostałych elementów systemu startowego sprężonego powietrza. Nie zarejestrowano żadnych sygnałów charakterystycznych dla przecieków i aktywnych procesów korozyjnych, co wskazuje na ich brak w badanej instalacji.

Wyniki badań pozwoliły wyciągnąć następujący wniosek - metoda EA może być przydatna do monitorowania stanu technicznego instalacji ciśnieniowych silników i urządzeń w siłowni okrętowej podczas normalnej pracy w czasie rzeczywistym.

\section{Literatura}

1. Dudzik K., Charchalis A.: Wykorzystanie emisji akustycznej do diagnozowania wtryskiwacza silnika 3AL25/30. Logistyka, No. 3, 2015.

2. https:/www.emerson.com/documents/automation/case-study-belgian-navy-savesbig-money-predictive-maintenance-based-on-vibration-monitoring-oil-analysis-amsen-38550.pdf

3. Minkina W.: Pomiary termowizyjne - przyrządy i metody. Wydawnictwo Politechniki Częstochowskiej, 2004.

4. Molenda J., Charchalis A.: The influence of the temperature of the elements of the lapping machine executory system on the results of the lapping process. Solid State Phenomena. 2015, Vols. 220-221.

5. Molenda J., Charchalis A.: Using thermovision for temperature measurements during turning process. Journal of Kones, Vol. 25, No. 4, 2018.

6. Pasagic V., Muzevic M., Kelenc D.: Infrared Thermography in Marine Applications. Brodogradnja, 2 (59), 2008.

7. Singh B.: Can effective predictive maintenance be more beneficial on board ships? Marine Insight (https://www.marineinsight.com/tech/predictive-maintenance-onboard-ships/). Updated April 2019. 